\title{
Equity-Efficiency Trade-Offs in Irrigation Water Sharing: Evidence from a Field Lab in Rural Tanzania
}

\author{
BEN D'EXELLE \\ University of East Anglia, United Kingdom \\ ELS LECOUTERE \\ Ghent University, Belgium
}

and

BJORN VAN CAMPENHOUT
IFPRI-Kampala, Uganda

\begin{abstract}
Summary. - This article studies how users of scarce common water resources deal with equity-efficiency trade-offs. For this purpose, we conduct a field lab experiment in Tanzania that simulates the distribution of irrigation water between upstream and downstream users. We find a strong preference for equal sharing even if this comes with large foregone efficiency gains. However, we also find indications that efficiency considerations are taken into account. (Selfish) deviations from equal sharing are more likely implemented when they are efficiency-enhancing. Finally, we detect a tendency to alternate between altruistic and selfish sharing, which reconciles equity and efficiency considerations.
\end{abstract}

(C) 2012 Elsevier Ltd. All rights reserved.

Key words - equity-efficiency trade-offs, egalitarian norms, distribution of irrigation water, field lab experiment, Tanzania

\section{INTRODUCTION}

Many people in Sub-Saharan Africa live in close-knit societies where their agency is strongly influenced by egalitarian norms. These norms may lead to socially superior behavior by inducing wealthier people to share their surplus with the less fortunate. At the same time, however, they can lead to considerable social efficiency losses, as they create conflicts in case of deviations from equal sharing (Grolleau, Mzoughi, \& Sutan, 2009), dampen economic aspirations to avoid envious reactions (Platteau, 2000, 2006) or make people reduce sharable savings to evade sharing obligations (Di Falco \& Bulte, 2011).

Such equity-efficiency trade-offs are very common in production systems that rely on common pool resources (CPR). Respect for equity norms is essential to build and reinforce trust and mutual commitment, which form the pillars of CPR self-governance (Ostrom, 1990); but it is often not evident to make the use of common resources both equitable and efficient (Baland \& Platteau, 1996; Ostrom \& Gardner, 1993). In this study, we will focus on irrigation water systems. Due to asymmetries in location, resource appropriation follows a "sequential" logic (Ostrom \& Gardner, 1993), which may further complicate the harmonization of efficiency and equity (Ray \& Williams, 2002).

There is ample literature that has studied efficiency and equity aspects of water use in irrigation systems. First, several studies have focused on the relation between water distribution and the efficiency of water use, and have demonstrated how temporal and spatial variation in water use may lead to a conflict between efficiency and equity (Chakravorty \& Roumasset, 1991; Ferguson, 1992; Lal Kalu, Nidhi Paudyal, \& Das Gupta, 1995). Second, other studies have focused on the collective action component within irrigation systems, and its consequences for equity and efficiency. Sufficient collective action is required to implement and monitor equitable water sharing, but also to maintain the quality of irrigation canals, necessary to guarantee an efficient water use (Baland \& Platteau, 1996; Bardhan, 2000; Meinzen-Dick, Raju, \& Gulati, 2002; Ray \& Williams, 2002; Wade, 1988).

While this literature has mainly focused on equity and efficiency at the system level, far less empirical research exists on the behavioral patterns of individual users interacting bilaterally with neighboring water users upstream or downstream in the irrigation system. People in irrigation channels often find themselves bargaining over the access to and use of (scarce) resources, and are not aware of the direct consequences of their individual decisions for the efficiency and equity of the whole system. Within such bilateral bargaining, the interactions of water users may be guided by norms of equity and considerations of efficiency. We are interested in examining how irrigation water users interact bilaterally to

\footnotetext{
${ }^{*}$ We gratefully acknowledge financial support from the Institute of Development Policy and Management (University of Antwerp), Ghent University, MICROCON and the Fonds voor Wetenschappelijk Onderzoek. We are also grateful for the support provided by Incomet 2001 and the excellent field support given by Charles Kyando. This research received research clearance from the Tanzania Commission for Science and Technology $(\mathrm{COSTECH})$ and the Mufindi District Council. We also benefited from the comments of Rembert De Blander, Franz Palm and Angelino Viceisza, as well as participants at the 2009 CSAE Conference at Oxford University, and the Workshop on the Workshop 2009 at Bloomington, Indiana University. This paper also benefited from the useful comments of three anonymous referees. Final revision accepted: May 25, 2012.
} 
deal with equity-efficiency tradeoffs when allocating irrigation water.

To do so, we conduct a series of distribution experiments with small farmers in rural Tanzania who depend on self-governed common irrigation schemes for water access, which determines their production and income (details of our experimental design are provided in Section 2). These farmers are used to a situation where users upstream in the irrigation scheme make appropriation decisions about the water flow, and in some cases are confronted with dropping water levels because upstream users use water excessively, even though sharing water equally is the norm. Moreover, in the dry season water in irrigation schemes becomes scarce, in a sense that it is technically impossible to give all irrigation users a water share that guarantees a decent production and income, leading to a conflict between equity and efficiency.

For these experiments, we group a sample of irrigation users in pairs of upstream and downstream users. In subsequent rounds, the upstream user is asked to decide on the number of hours to make use of a constant water flow. After each distribution decision, the downstream user has the option to remain silent, to react in the form of expressing (dis)satisfaction or to engage in costly punishment of the upstream user. We compare between a treatment with abundant water availability ("abundance treatment") and a treatment where water is insufficient for both players to reach a minimum production threshold ("scarcity treatment"), which creates an important equity-efficiency trade-off.

An important reason for using an experiment to analyze bargaining over water access is that we can do it in a controlled way. In rural communities, equity norms are applied to a broad range of social interactions, which are often interlocked, so that equitable water allocation possibly interacts with other social interactions where equity norms are applied (Baland \& Platteau, 1996, 1998; Cochran \& Ray, 2009). To investigate how equity in water distribution and possible efficiency implications influence water allocation by irrigation users, the controlled environment of an experiment is very helpful. It allows us to focus on one particular aspect of the complex and interlocked interactions in rural communities while minimizing the influence of other aspects. ${ }^{1}$

Such an experimental approach is not new in development studies. Several studies have brought behavioral games from the computer lab, where they have been commonly used with university students, to the field lab (for an overview see Cardenas and Carpenter (2008)). A very common distribution game is the ultimatum game (Güth, Schmittberger, \& Schwarze, 1982), where two subjects bargain over the distribution of a given amount of resources, and which has been replicated across many different cultures and settings (see e.g., Henrich et al., 2004). Of particular interest for the purpose of our study is Gowdy, Iorgulescu, and Onyeiwu (2003) who with the help of an ultimatum game in rural Nigeria found strong evidence in support of an internalized concern for equity.

While these studies have used abstract, context-free instructions - as is the rule in experiments with university studentsfield referents may be needed to link behavior in experimental games with life outside the field lab, in order to increase internal and external validity. ${ }^{2}$ A recent example of such approach is a study of Cardenas, Rodriguez, and Johnson (2011), who analyzed the strategic interaction among irrigation users in Colombia and Kenya. They found that the asymmetric resource appropriation that characterizes irrigation water systems lowers cooperation among water users.

In Section 3, we present our results. We find that many people prefer equal sharing even if this leads to high efficiency losses. While equal sharing of irrigation water prevails in the abundance treatment, even in a treatment that simulates acute water scarcity, equal sharing remains the most preferred option, despite the very high foregone efficiency gains. At the same time, however, selfish (and efficiency-enhancing) deviations from equal sharing are more likely in the scarcity treatment. In a considerable number of cases downstream users express satisfaction with such distributions (much more than in the abundance treatment). Furthermore, in the scarcity treatment upstream users show a tendency to alternate as to who receives a share above the production threshold. This is an important observation as such alternation makes it possible to reconcile equity and efficiency considerations.

\section{RESEARCH DESIGN}

The experiment aims to reproduce important incentives that the participants face in their daily life when they bargain over access to an irrigation water flow. The participants are often confronted with dropping water levels as water users upstream in the irrigation scheme overuse or even cut off water channels. In such occasion, they try to induce upstream users to reconsider and adapt their distribution decisions.

\section{(a) The participants}

The experiment was run in July-August 2008 in the semiarid lowland areas of Mufindi district in Tanzania, where water is scarce from May until November (United Republic of Tanzania, 2006a). Most rural households in this area depend on semi-subsistence smallholder farming and (small) livestock. Agricultural production is mainly based on rain-fed cultivation. Irrigated agriculture is used to produce food and cash crops outside of the season. As a consequence, access to irrigation water influences food security and income, the more so in the dry season when water becomes scarce (Mkavidanda \& Kaswamila, 2001; United Republic of Tanzania, 2006b).

In this region, we selected five self-governed irrigation systems that consist of a network of locally dug river diversions and small canals that divert a water flow to a patchwork of plots, most of which are relatively small. Canals and river diversions are dug collectively or on the initiative of a few individuals. Usually, irrigators are expected to contribute to canal maintenance. Fixed rules regarding water appropriation are largely absent. Often, irrigators individually decide on water appropriation. Sometimes, they informally agree on water sharing or make up a rotation scheme. Generally, competition and distributive conflicts are avoided in order to maintain harmony. A fair distribution of irrigation water is regarded essential.

A week before the experiment, we organized in each of the irrigation sites a participatory exercise with mixed groups of irrigators to map and identify all irrigation water users. From these censuses random samples of irrigators were selected to participate in the experiments. ${ }^{3}$ Important information on these participants' socio-economic characteristics and experiences in the irrigation system was collected with a questionnaire. Table 1 presents the main socio-economic characteristics. On average $29 \%$ of the total land used by households is irrigated. Irrigated plots are mainly used to cultivate food crops such as maize, beans, and sweet potato, and to a lower extent crops for local marketing such as tomatoes and other vegetables (carrot, cabbage, sugarcane, African eggplant, etc). 
Table 1. Descriptive statistics of individual and household characteristics

\begin{tabular}{|c|c|c|}
\hline & Mean/percentage & St. dev. \\
\hline \multicolumn{3}{|l|}{ Individual characteristics } \\
\hline Female & $33.33 \%$ & \\
\hline Age & 43.44 & 13.43 \\
\hline No education & $17.11 \%$ & \\
\hline Primary education (completed) & $70.51 \%$ & \\
\hline Lifetime residents & $80.65 \%$ & \\
\hline \multicolumn{3}{|l|}{ Household characteristics } \\
\hline Household size (number of persons) & 5.68 & 2.32 \\
\hline Experienced food insecurity in the last 2 years & $34.62 \%$ & \\
\hline House has iron roof & $58.00 \%$ & \\
\hline Household owns bicycle & $64.00 \%$ & \\
\hline Household owns cows & $18.83 \%$ & \\
\hline Livestock value (in US\$) ${ }^{\mathrm{a}}$ & 407 & 734 \\
\hline Total land (in acres) & 5.41 & 4.41 \\
\hline Proportion of total land that is irrigated & 0.29 & 0.20 \\
\hline Proportion of irrigated land planted with food crops & 0.71 & 0.28 \\
\hline Proportion of irrigated land planted with cash crops & 0.13 & 0.20 \\
\hline
\end{tabular}

Note: $N=156$.

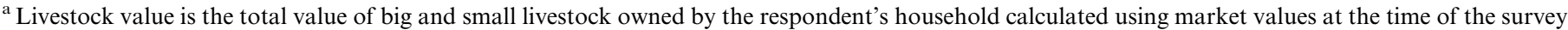
(www.lmistz.net and market prices recorded in Mufindi district, July 2008). At the time of the survey 1 US\$ was equal to 1200 TSH.

We also collected information about irrigation water problems. $19.2 \%$ of the 156 respondents reported one or more problems with irrigation water in the season before the interview, and $43.6 \%$ had at least one such problem over the last 5 years. The most frequently reported problems are insufficient water supply for irrigation, upstream users using too much water, or closing off the water supply, and other users disrespecting water allocation agreements.

\section{(b) Bargaining over water access: the game}

In the experiment, participants are randomly assigned the role of upstream or downstream (water) user and anonymously paired up. ${ }^{4}$ The experiment consists of several rounds. In each round, the upstream user takes as much water as he or she wants from a constant water flow, and what is left flows to the downstream user. More specifically, the upstream user decides how many hours in a day (of a maximum of $12 \mathrm{~h}$ ) to take water from the irrigation canal. While the upstream user taps water, it is assumed that no water flows to the downstream user. There is a direct relation between water use and income, represented by the production function in Table 2. As irrigation-dependent production requires a critical water input, this production function is characterized by a threshold. In the second column of Table 2, for example, we observe that the production of the upstream user drastically increases with at least $4 \mathrm{~h}$ water use (from 50 to $175 \mathrm{TSH}$ ). This threshold represents a minimum water use below which production is equal to a low level irrespective of the exact water input. In addition, above this critical water input, production shows decreasing marginal returns. ${ }^{5}$

We organize two treatments that differ on the water flow. In a water scarcity treatment, the water flow is approximately half as large as in the abundance treatment, so that more hours are needed to exceed the production threshold $(7 \mathrm{~h}$ instead of $4 \mathrm{~h}$ ). At the same time, beyond this threshold, declines in marginal returns are less drastic with increasing number of hours of water use. Parameters are such that, in the abundance treatment, total water availability is sufficient for both water users to reach the minimum water input, whereas in the scarcity treatment, total water availability is insufficient for both users to reach this threshold. As a consequence, in the scarcity treatment there is a conflict between efficiency and equity. Distributing access to irrigation water equally, leads to the lowest aggregate income (i.e., 100 TSH), whereas maximizing inequality by excluding one water user completely from access to irrigation water leads to the highest aggregate income (i.e., $400 \mathrm{TSH}$ ).

After the allocation decision made by the upstream user, downstream users are given the option to react to the upstream user's decision. To design a realistic range of reaction options, we used evidence from focus group discussions on how irrigators have dealt with conflicts in the recent past. Consistent with Ostrom (1990), we identified a preference for mutual monitoring and gradual sanctioning over punishment mechanisms, unless rule breaking is substantial. Translating this to our experiment, downstream users were asked to choose one of the following reactions. First, downstream users can punish upstream users by reducing their payoff by 100 $\mathrm{TSH}$. The cost of this option is $30 \mathrm{TSH}$ for the downstream

Table 2. Upstream and downstream users' pay-offs

\begin{tabular}{lccccc}
\hline \multirow{2}{*}{$\begin{array}{l}\text { Hours upstream } \\
\text { user }\end{array}$} & \multicolumn{2}{c}{ (a) Water abundance } & & \multicolumn{2}{c}{ (b) Water scarcity } \\
\cline { 2 - 3 } \cline { 5 - 6 } & Upstream & Downstream & & Upstream & Downstream \\
\hline 0 & 50 & 500 & & 50 & 350 \\
1 & 50 & 500 & & 50 & 325 \\
2 & 50 & 475 & & 50 & 300 \\
3 & 50 & 450 & & 50 & 250 \\
4 & 175 & 425 & & 50 & 200 \\
5 & 250 & 375 & & 50 & 125 \\
6 & 325 & 325 & & 50 & 50 \\
7 & 375 & 250 & & 125 & 50 \\
8 & 425 & 175 & & 200 & 50 \\
9 & 450 & 50 & & 250 & 50 \\
10 & 475 & 50 & & 300 & 50 \\
11 & 500 & 50 & 325 & 50 \\
12 & 500 & 50 & 350 & 50 \\
\hline
\end{tabular}

Note: Pay-offs are measured in Tanzanian Shilling (TSH), with 1 US\$ = $1200 \mathrm{TSH}$ 
user. The punishment option is not framed as direct punishment, which would be too intrusive an instrument in these societies. Instead, downstream users are told they can rely on a local mediator who would then punish the upstream user. Second, we also included the following three less conflictive response options, which leave individual payoffs unaffected: to communicate satisfaction, to communicate dissatisfaction, or to remain silent. 6

The game is repeated during five rounds in the abundance treatment and 10 rounds in the scarcity treatment. All participants played both treatments. The participants did not know in advance the number of rounds in each treatment, in order to avoid end-game effects created by participants' strategic behavior; nor did they know that after the first treatment a second treatment would follow with a different pay-off table. ${ }^{7}$

\section{(c) What behavior to expect}

In this section, we will describe how the behavior of upstream and downstream users may be influenced by material self-interest (income maximization), equity, and efficiency, and how the experimental design allows us to study the role of these behavioral motives. ${ }^{8}$ One common reference point for distribution experiments is the one-shot Nash equilibrium under the assumption of (common knowledge of) narrow material self-interest. As punishment is costly, an income-maximizing downstream user would always refrain from punishing the upstream user irrespective of the distribution. Consequently, the upstream user, anticipating this, will appropriate as much water as to maximize his/her pay-off (i.e., at least $11 \mathrm{~h}$ in the abundance treatment and $12 \mathrm{~h}$ in the scarcity treatment). ${ }^{9}$

However, the many replications of the ultimatum game, which resembles our irrigation game, have demonstrated that this assumption of narrow material self-interest is not very realistic, and that people also take the well-being of others into account (for surveys see, e.g., Camerer, 2003; Cooper \& Kagel, 2010). Receivers care about equity as they give up part of their income (by using a costly punishment option) to reduce inequality. This has been rationalized by new economic models where individual utility reduces with larger inequality (e.g., Bolton \& Ockenfels, 2000; Fehr \& Schmidt, 1999). In order to avoid such punishment, distributors offer more equal distributions.

As this evidence is mainly based on studies in Western societies, the following two important elements should be taken into account. First, the evidence contrasts with ultimatum game studies in African societies. Gowdy et al. (2003), for example, found through follow-up interviews that an internalized concern for equity and not fear of retaliation was the overwhelming reason for equal sharing in rural Nigeria. Evidence from bargaining experiments at Western Universities, in contrast, suggests that distributors in Western societies tend to apply equity considerations in a strategic way-i.e., only to "appear fair" in order to avoid possible retaliation by others (see e.g., Forsythe, Horowitz, Savin, \& Sefton, 1994; Pilutla \& Murnighan, 1995), but less because of a preference for equity.

Second, in small-scale irrigation communities, a preference for equity does not necessarily make downstream users punish upstream users who keep more than an equal share. As Ostrom (1990) documented, mutual monitoring and gradual sanctioning is often preferred over trigger punishment mechanisms which could provoke resentment and unwillingness to rule compliance in the future. These are avoided because one would want some understanding at the time one faces similar problems and breaks the rules. In sum, whereas equal sharing in African irrigation communities may be equally prominent as in Western industrialized societies, the behavioral motives behind it are surely different.

Besides self-interest and equity considerations, efficiency considerations may influence the behavior of upstream and downstream users. Some studies have indeed demonstrated that efficiency considerations may be taken into account when resources are distributed (see e.g., Charness \& Rabin, 2002; Engelmann \& Strobel, 2004). This is of particular relevance in the scarcity treatment of our experiment, where deviating from equal sharing increases aggregate income (in the abundance treatment it leads to virtually equal or lower aggregate income). In both treatments, upstream users face a trade-off between self-interest and equity. They could increase their income by keeping more than an equal share, but this obviously increases inequality. Therefore, a comparison across both treatments allows us to study how efficiency considerations influence the balance between self-interest and equity. In particular, we expect that upstream users who care about efficiency are more likely to deviate from equal sharing (in a selfish way).

Our design also allows us to analyze trade-offs between equity and self-interest, and between equity and efficiency. First, in the abundance treatment, there is a range of allocations where upstream and downstream users receive water shares above the minimum threshold (between 4 and $8 \mathrm{~h}$ for each water user), so that aggregate income remains virtually constant (and efficiency cannot be a matter of concern). In this area, a conflict possibly exists between individual income maximization and equity, as the income of one player can only be increased by lowering the income of the other player. Given the strong egalitarian norms in African societies (e.g., Gowdy et al., 2003; Platteau, 2000, 2006) we expect that many upstream users will propose the equal split. Second, in the scarcity treatment, the income of the downstream user remains fixed (at $50 \mathrm{TSH}$ ) no matter how much the upstream user keeps above the equal split. As a consequence, in this range of allocations individual income maximization cannot be a matter of concern for the downstream user. However, as aggregate income increases with larger deviations from equal sharing, the downstream user might still face a trade-off between equity and efficiency. Assuming that inequality reduces individual utility (in accordance with the model of Fehr and Schmidt (1999), for example), downstream users will only accept more inequality if it comes with a benefit. Therefore, only those downstream users who value efficiency will accept that upstream users use more than an equal share.

Finally, the data allow us to test whether more advanced alternation strategies are followed in an attempt to reconcile equity and efficiency. In the scarcity treatment, any symmetric alternation strategy between altruistic and selfish sharing is an equilibrium that is superior to equal sharing. To see this, assume that in two consecutive rounds water access is equally distributed such that $\left(h_{1}=6, h_{2}=6\right)$, with $h_{\mathrm{i}}$ being the hours of water use for the upstream user in round $i$. Comparing such sequence with sequences $\left(h_{1}>6, h_{2}<6\right)$ or $\left(h_{1}<6, h_{2}>6\right)$ with $\left(h_{1}-6\right)+\left(h_{2}-6\right)=0$, the latter sequences lead to a higher accumulated pay-off for both players. Moreover, the symmetric nature of the alternation sequence removes any inequity, as the inequalities counterbalance each other. ${ }^{10} \mathrm{As}$ a consequence, if our participants care about efficiency, we expect such alternation to be much more common in the scarcity treatment than in the abundance treatment.

To analyze the data we pool both treatments and use a regression approach, which allows us to control for the water 
distribution, the treatment and the interactions between the treatment and the water distribution. By doing so, we are able to analyze the importance of considerations of individual income maximization, equity, and efficiency. Such approach also allows us to analyze dynamic effects, such as state dependence (and alternation strategies) in the decisions of the upstream user, and the upstream user's strategy change in response to the downstream user's reaction.

\section{(d) The experiments}

Each session of the experiment began with a welcoming act, after which it was explained to the participants that participation was voluntary, the experiment would take around two hours of their time, and their decisions in the experiment would be dealt with in a confidential way. It was told that the money they would earn would be paid out privately and confidentially after the exercise. The instructions were then read by a monitor to the participants. (The instructions are available upon request from the authors.) Because of the low literacy of many participants, no written instructions were given, except a table with the production function (part (a) or (b) of Table 2 depending on the treatment). The instructions had been pre-tested and adapted to make sure that they would be understandable to illiterate participants. They explained the procedures of the game and how income was earned. To familiarize the participants with the game and the procedures we used several examples. In addition, we included several control questions which allowed us to identify participants who required more support to understand the instructions.

In each round, upstream users would choose how many hours, $h \in[0,12]$, they make use of the irrigation water flow and wrote this decision on a slip of paper. After all upstream users had made their decision one of the monitors collected the slips of paper and gave them to the corresponding downstream users. The latter were then asked to decide on their reaction and to write this on the same slip of paper, which was then returned to the upstream users. It was made sure that during the whole exercise participants would not discover with whom they were matched. To guarantee complete anonymity among the participants each session of the experiment involved three monitors and a minimum of eight participants. We did not allow more than 14 participants, so that the monitors could provide additional assistance to illiterate participants. In addition, enough space was left between the chairs used by the participants so that they could not observe others' decisions. During the whole exercise, participants were not allowed to communicate with each other. If they had a question, they were asked to raise their hand, so that one of the monitors could come and answer their question in private. In total, 156 irrigation users participated in the experiment in 13 different sessions, distributed over the five irrigation systems. Average earnings were $2460 \mathrm{TSH}$, equal to $1.37 \mathrm{US} \$$, i.e., around two days average income.

After the experiment, via a short individual questionnaire we asked the participants how much the experiment resembled real life and we found that only $8.3 \%$ of them did not recognize anything from real life. In post-experimental group discussions most participants actually recognized that several aspects of the game resemble what occurs in real-life. Some of them referred to the necessity of equal sharing to avoid conflicts in both water abundance and water scarcity situations, and recognized that some people are selfish when it comes to water use. They also mentioned that communicating dissatisfaction to upstream users may be an effective way to lower the selfishness of upstream users.

\section{RESULTS}

We start this section with an analysis of the upstream and downstream users' behavior in both treatments. We then investigate downstream users' reaction to the strategy chosen by upstream users, by estimating probabilities of the downstream user's reactions conditional on the distribution chosen by the upstream user. Thereafter, we look at the distribution decisions of upstream users, conditional on their strategy chosen in the previous round and downstream users' reaction. This allows us to analyze possible alternation strategies, which reconcile equity and efficiency considerations.

\section{(a) A first look at upstream and downstream users' strategy choice}

Figure 1 shows the distribution of upstream users' decisions. In the abundance treatment, we observe that upstream users choose for "equal sharing" $(h=6)$ and "altruistic sharing" $(h<6)$ in more than $30 \%$ and $35 \%$ of the decisions, respectively. As upstream users could easily and substantially increase their pay-off by opting for "selfish sharing" $(h>6)$, other considerations than self-interest must have influenced their allocation decision. ${ }^{11}$ Note that efficiency considerations cannot have influenced upstream users' decisions within the area [4.8], where aggregate income remains virtually the same. ${ }^{2}$ The only plausible explanation for the low frequency of selfish sharing is an aversion from selfishness, which is consistent with the strong egalitarian norms that characterize these societies.

In the scarcity treatment, equal sharing remains the mode. In contrast to the abundance treatment where deviating from equal sharing does not increase aggregate income, any deviation from equal sharing in the scarcity treatment automatically increases aggregate income. Consequently, choosing the equal split in the scarcity treatment leaves a lot of the resources unexploited. At the same time, however, we observe a shift toward more hours of water use by the upstream user. Comparing between both treatments the frequencies of allocations of altruistic sharing, equal sharing, and selfish sharing for each upstream user and applying a Wilcoxon signed ranks test, we find that altruistic sharing is significantly less frequent in the scarcity treatment (two-sided $P$-value $=.003$ ) and selfish sharing is significantly more common (two-sided $P$-value $=.015$ ). The difference in the frequencies of equal sharing between both treatments is only marginally significant (twosided $P$-value $=.075$ ).

While selfish sharing is more common in the scarcity treatment, we observe that in many occasions upstream users decide not to deviate too much from equal sharing (in a selfish way). The second most commonly chosen option is $7 \mathrm{~h}$ for the upstream user, while larger deviations from equal sharing are substantially less common. This makes us conclude that the efficiency implications in the scarcity treatment (which are absent in the abundance treatment) make upstream users more inclined to (modestly) deviate from equal sharing in a selfish way. Apparently, the efficiency implications shift the balance between self-interest and equity, making small (selfish) deviations from equal sharing acceptable if they have positive efficiency implications.

The lower frequency of altruistic sharing in the scarcity treatment may be driven by a similar mechanism. If altruistic sharing in the abundance treatment is chosen because of an aversion from selfishness, the additional efficiency gains in the scarcity treatment obtained when deviating from equal sharing, may shift the balance between self-interest and selfishness (making 


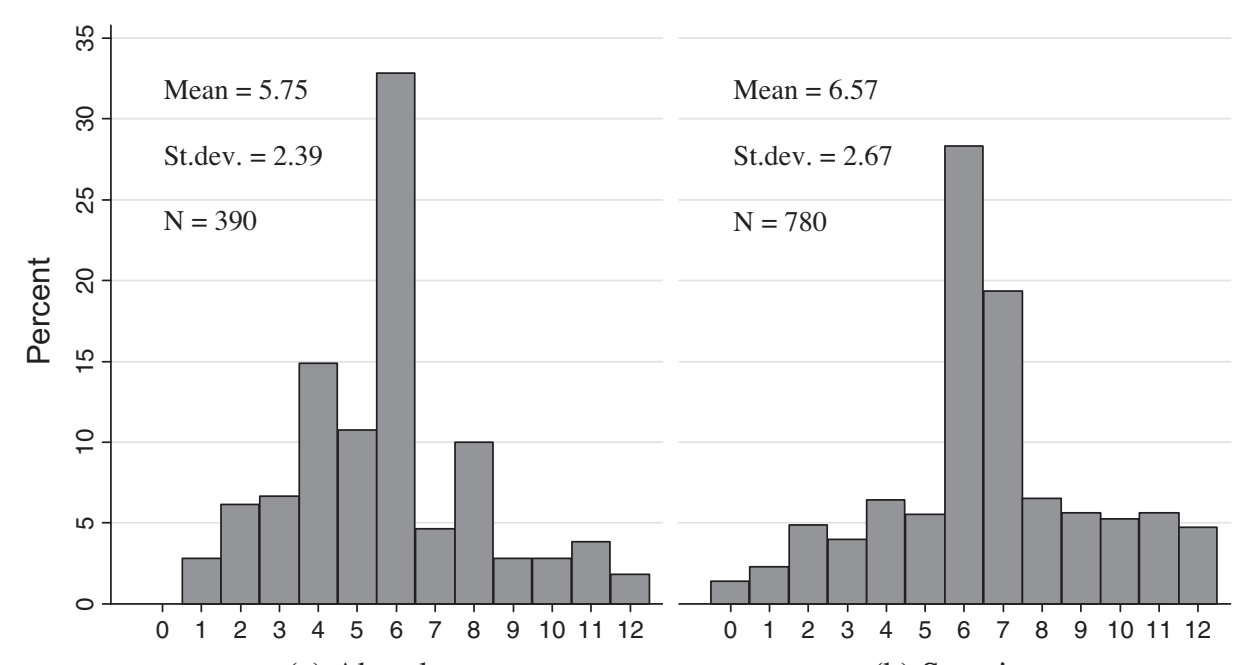

(a) Abundance

(b) Scarcity

Figure 1. Hours of water for upstream user.

selfish sharing more acceptable), and hence make upstream users shift from altruistic to selfish sharing. It is also plausible, however, that people who share altruistically in the abundance treatment switch to an "alternation strategy" in the scarcity treatment. As explained before, alternating between altruistic and selfish sharing is the most optimal strategy in the scarcity treatment as it reconciles equity and efficiency considerations. $^{13}$

We now look at the reaction of the downstream user. Table 3 shows the decisions made by the downstream users. We find that the punishment option is the least frequently used option in both treatments $(12.85 \%$ and $16.17 \%$ in the abundance and scarcity treatments, respectively). The option of expressing dissatisfaction is more commonly used, and more frequently in the scarcity treatment $(27.09 \%)$ than in the abundance treatment $(16.97 \%)$. We also observe that in the abundance treatment around half of the downstream users' reactions $(53.47 \%)$ consist of expressing satisfaction, a percentage which decreases to $39.67 \%$ in the scarcity treatment. To test whether the frequencies of the downstream user's strategies differ between both treatments, we calculate the proportion of each of these strategies per downstream user in each of both treatments and apply a Wilcoxon signed ranks test. According to the test results, downstream users express significantly less often their satisfaction (two-sided $P$-value $=.009$ ) in the scarcity treatment and significantly more often their dissatisfaction (two-sided $P$-value $=.076$ ). The relative frequency of the punishment strategy, however, is not significantly different between both treatments (two-sided $P$-value $=.808$ ). Also the use of the "remaining silent" option does not significantly vary between both treatments (two-sided $P$-value $=.149$ ). We sum-

Table 3. Descriptive statistics of downstream user reaction

\begin{tabular}{lccccc}
\hline & \multicolumn{2}{c}{ Abundance } & & \multicolumn{2}{c}{ Scarcity } \\
\cline { 2 - 3 } \cline { 5 - 6 } & Freq. & Percent $(\%)$ & & Freq. & Percent $(\%)$ \\
\hline Punishment & 50 & 12.85 & & 126 & 16.17 \\
Dissatisfaction & 66 & 16.97 & & 211 & 27.09 \\
Silent & 65 & 16.71 & & 133 & 17.07 \\
Satisfaction & 208 & 53.47 & & 309 & 39.67 \\
Total & 389 & 100.00 & & 779 & 100.00 \\
\hline
\end{tabular}

marize the main observations discussed so far in the following result.

Result 1: Equal sharing is the most prominent allocation in both treatments. In the scarcity treatment, selfish sharing is more frequent than in the abundance treatment, but deviations remain modest. Dissatisfaction rates are higher in the scarcity treatment, while punishment rates are similar.

\section{(b) Reaction of downstream users}

In the analysis of the downstream users' reaction, so far we only looked at the treatment effect. Such effect, however, may work through two distinct mechanisms. It may be the result of (1) differences in upstream users' distribution behavior between both treatments and (2) differences between both treatments in downstream users' reaction to a given distribution. To disentangle both effects, we model downstream users' reaction being dependent on both the upstream users' distribution behavior and the treatment. To do so, we pool both treatments and estimate a probit regression for each of the possible downstream users' reactions. We include the following explanatory variables in the model.

We control for the treatment condition and the following four ranges of unequal sharing. Two ranges of selfish sharing (from the upstream user's point of view): $h \in] 6,8]$ and $h \in] 8,12]$; and two ranges of altruistic sharing: $h \in[4,6[$ and $h \in[0,4[$. We omit the case where water access is equally shared $(h=6)$, which makes this the reference outcome. We also include interaction terms between the treatment condition and each range of unequal sharing.

This specification allows us to investigate the influence of considerations of equity and individual income on the downstream user's reaction. It seems intuitive that with strong sharing norms downstream users are more inclined to express dissatisfaction or even to choose the punishment option if the upstream user keeps more than an equal share. Furthermore, because of the threshold in the production function and a potential influence of efficiency considerations it may matter whether water users receive a share above or below the threshold.

Table 4 shows the results of the probit regressions. To interpret the size of the estimated effects we convert the coefficients into predicted probabilities (reported in Table 5). We only 
report on the significant results. In the abundance treatment, we find that when upstream users deviate from the equal split so that $h \in] 6,8]$ the likelihood that downstream users express satisfaction lowers (from $60.75 \%$ to $24.12 \%$ ) and the likelihood that they express dissatisfaction increases (from $11.92 \%$ to $38.39 \%){ }^{14}$ It also makes it more likely that they make use of the punishment option (from $5.09 \%$ to $22.08 \%$ ). As in the range $h \in] 6,8$ ] aggregate income remains virtually the same, only income maximization and equity considerations can rationalize downstream users' reaction (efficiency cannot be a matter of concern). Therefore, this result indicates that downstream users care about equity, as they are willing to give up some of their income to reduce inequality (by choosing the costly punishment option the income of the upstream users is reduced more than the income of the downstream user, lowering income inequality). The likelihood that downstream users choose the punishment option more than doubles (from $22.08 \%$ to $51.53 \%$ ) for larger deviations from equal sharing (i.e., $h \in] 8,12]$.

In the scarcity treatment, we observe a similar reduction in the likelihood of satisfaction and a similar increase in the likelihood of punishment and expression of dissatisfaction as observed in the abundance treatment. For example, for $h \epsilon] 6,8]$ the likelihood of dissatisfaction and punishment is $44.87 \%$ and $18.21 \%$, respectively, compared to $13.40 \%$ and $3.95 \%$ in case of equal sharing. With stronger deviations from equal sharing (with $h \in] 8,12]$ ) the likelihood of punishment increases further $(44.76 \%)$. The likelihood to express satisfaction, however, remains considerable $(21.23 \%)$; the latter suggests that some downstream users accept larger inequality if it comes with larger aggregate income (efficiency). Note that the income of the downstream user in the range $h \in] 6,12]$ is the same as with equal sharing. Hence, income maximization cannot be a matter of concern and the downstream user's reaction can only be driven by considerations of efficiency and equity. We summarize the main observations on the downstream user's strategy choice in the following result.

Result 2: In both treatments, selfish deviations from equal sharing make downstream users less inclined to express satisfaction, and more inclined to express dissatisfaction and to make use of the punishment option. In the scarcity treatment, the most selfish allocation, which maximizes both inequality and efficiency, still comes with a considerable likelihood to express satisfaction.

\section{(c) Distribution behavior of upstream users}

We now investigate the strategies followed by the upstream user. In particular, we study the state dependence of upstream users' strategy choice and possible alternation between selfish and altruistic sharing. As described before, equity and efficiency considerations can be reconciled if upstream users alternate between distributions of $h>6$ and $h<6$ in consecutive rounds. To study state dependence and possible alternation, we estimate a probit regression, controlling for the allocation in the previous round. This allows us to study the likelihood that an upstream user persists with a particular allocation or switches between different allocations.

In particular, we estimate five different models, each one corresponding to one of the five ranges of interest: $h \in] 8,12]$, $h \in] 6,8], h=6, h \in[4,6[$ and $h \in[0,4[$. Each model estimates the likelihood that upstream users choose a distribution vector that lies in the respective range. To investigate state dependence and possible alternation, we include the dummy variables " $h(r-1) \epsilon] 8,12] ", " h(r-1) \epsilon] 6,8] ", " ~ h(r-1) \in[4,6["$ and " $h(r-1) \in[0,4[$ " which control for the hours of water access in the previous round $r-1$. We omit the possibility $h(r-1)=6$, which makes it the reference category.

As we are using repeated measurements on the same individuals, the residuals from standard regressions are likely to be correlated within individuals. To account for this individual specific unobserved heterogeneity, we use a panel data model. More specifically, we allow for an individual specific component in a composed error term. Such an approach, where sampled subjects are modeled as random effects, while variables that are under control of the experimenter (e.g., treatment condition) are modeled as fixed parameters, is standard when modeling experimental data (Pinheiro \& Bates, 2000).

If we look at the allocation decision of the upstream user as a function of the allocation decision in the previous round (as we do in our model), the allocation in the previous round may be correlated with the error term, which leads to an endogeneity bias. This can be seen by decomposing the residual $\mu_{i, r}$ in an unobserved individual specific effect that is time-invariant $\alpha_{i}$ and a time-dependent residual term $\varepsilon_{i, r}$, and noting the potential correlation between the lagged dependent variable and the composed error term $\mu_{i, r}$ through the individual specific effects $\alpha_{i}$. Since we cannot eliminate the unobserved heterogeneity $\alpha_{i}$, the estimation of this specification requires an assumption about the relationship between the observations of the (latent) variable in round $r=1$ and $\alpha_{i}$. However, if we can assume that the initial observations are exogenous, a standard random effects model can be estimated, since the likelihood can be decomposed into two independent factors and the joint probability for rounds $r=2, \ldots, T$ maximized without reference to that for the initial round $r=1$ (Stewart, 2006). Such exogeneity assumption is plausible if the start of the process coincides with the start of the observation period for each individual, which is the case for our experimental data.

We also control for the treatment condition and its interaction with the allocation decision in the previous round. Decisions in the first round in both treatments are not included. Table 6 presents the results. To be able to interpret the size of the effects we convert the estimated coefficients into predicted probabilities. Table 7 shows the results, in the form of a "transition matrix". We only report on the significant results.

In the abundance treatment, we observe strong state dependence for the altruistic sharing strategies. The likelihoods that upstream users stick to $h \in[0,4[$ and $h \in[4,6[$ are $44.74 \%$ and $65.97 \%$, respectively. We observe weaker state dependence for these strategies in the scarcity treatment $(16.70 \%$ and $26.72 \%$, respectively). This result is explained by the fact that in the scarcity treatment it becomes interesting to alternate between altruistic and selfish sharing. We indeed find that the likelihood to switch from altruistic to selfish sharing is substantially higher in the scarcity treatment. In the abundance treatment the likelihoods of switching from $h \in[4,6[$ or $h \in[0,4[$ to $h \in[8,12$ [ are only $2.50 \%$ and $0.00 \%$, respectively, whereas in the scarcity treatment they increase to $25.95 \%$ and $18.38 \%$, respectively. Similarly, the likelihoods of switching from $h \in[4,6[$ or $h \in[0,4[$ to $h \in] 6,8]$ increase from $9.78 \%$ and $7.25 \%$ in the abundance treatment to $11.66 \%$ and $18.21 \%$ in the scarcity treatment.

Also the likelihood of switching from selfish to altruistic sharing is substantially higher in the scarcity treatment. Whereas in the abundance treatment the likelihoods of switching from $h \in] 8,12]$ to $h \in[4,6[$ and $h \in[0,4[$ are $3.41 \%$ and $9.04 \%$, respectively, in the scarcity treatment these likelihoods increase to $8.97 \%$ and $17.29 \%$. For the likelihoods of switching from $h \in] 6,8]$ to $h \in[4,6[$ and $h \in[0,4[$ the differences between both treatments are weaker. In the abundance treatment, these 
Table 4. Downstream users' reaction

\begin{tabular}{|c|c|c|c|c|}
\hline & $\begin{array}{c}(1) \\
\text { Satisfaction }\end{array}$ & $\begin{array}{c}(2) \\
\text { Silent }\end{array}$ & $\begin{array}{c}(3) \\
\text { Dissatisf. }\end{array}$ & $\begin{array}{c}\text { (4) } \\
\text { Punishment }\end{array}$ \\
\hline Scarcity (dummy) & $\begin{array}{c}-0.522^{* *} \\
(0.213)\end{array}$ & $\begin{array}{l}0.466^{* *} \\
(0.235)\end{array}$ & $\begin{array}{c}0.111 \\
(0.252)\end{array}$ & $\begin{array}{l}-0.205 \\
(0.422)\end{array}$ \\
\hline$h \in] 8,12]$ & $\begin{array}{c}-3.433^{* * *} \\
(0.591)\end{array}$ & $\begin{array}{c}-0.993^{* *} \\
(0.446)\end{array}$ & $\begin{array}{l}1.150^{* * *} \\
(0.306)\end{array}$ & $\begin{array}{l}2.853^{* * *} \\
(0.443)\end{array}$ \\
\hline$h \in] 6,8]$ & $\begin{array}{c}-1.854^{* * *} \\
(0.312)\end{array}$ & $\begin{array}{l}0.0769 \\
(0.321)\end{array}$ & $\begin{array}{l}1.384^{* * *} \\
(0.305)\end{array}$ & $\begin{array}{l}1.477^{* * *} \\
(0.425)\end{array}$ \\
\hline$h \in[4,6[$ & $\begin{array}{c}0.332 \\
(0.270)\end{array}$ & $\begin{array}{c}-0.0133 \\
(0.301)\end{array}$ & $\begin{array}{c}-0.797^{* *} \\
(0.367)\end{array}$ & $\begin{array}{c}0.541 \\
(0.425)\end{array}$ \\
\hline$h \in[0,4[$ & $\begin{array}{c}0.372 \\
(0.349)\end{array}$ & $\begin{array}{l}-0.333 \\
(0.363)\end{array}$ & $\begin{array}{c}0.375 \\
(0.378)\end{array}$ & $\begin{array}{l}-0.346 \\
(0.597)\end{array}$ \\
\hline$h \in] 8,12] \times$ scarcity & $\begin{array}{l}1.920^{* * *} \\
(0.605)\end{array}$ & $\begin{array}{l}-0.432 \\
(0.513)\end{array}$ & $\begin{array}{l}-0.201 \\
(0.357)\end{array}$ & $\begin{array}{c}-0.0844 \\
(0.504)\end{array}$ \\
\hline$h \in] 6,8] \times$ scarcity & $\begin{array}{l}0.640^{*} \\
(0.362)\end{array}$ & $\begin{array}{c}-1.070^{* * *} \\
(0.388)\end{array}$ & $\begin{array}{c}0.149 \\
(0.357)\end{array}$ & $\begin{array}{c}-0.0296 \\
(0.524)\end{array}$ \\
\hline$h \in[4,6[\times$ scarcity & $\begin{array}{l}-0.198 \\
(0.363)\end{array}$ & $\begin{array}{l}-0.315 \\
(0.387)\end{array}$ & $\begin{array}{l}1.225^{* * *} \\
(0.468)\end{array}$ & $\begin{array}{l}-1.293 \\
(0.897)\end{array}$ \\
\hline$h \in[0,4[\times$ scarcity & $\begin{array}{c}0.197 \\
(0.400)\end{array}$ & $\begin{array}{l}0.0226 \\
(0.426)\end{array}$ & $\begin{array}{l}-0.430 \\
(0.480)\end{array}$ & $\begin{array}{l}-0.363 \\
(0.828)\end{array}$ \\
\hline Constant & $\begin{array}{l}1.041^{* *} \\
(0.409)\end{array}$ & $\begin{array}{c}-2.063^{* * *} \\
(0.455)\end{array}$ & $\begin{array}{c}-1.958^{* * *} \\
(0.454)\end{array}$ & $\begin{array}{c}-2.583^{* * *} \\
(0.720)\end{array}$ \\
\hline Observations & 1170 & 1170 & 1170 & 1168 \\
\hline chi2 & 187.6 & 38.72 & 118.0 & 108.3 \\
\hline Prob $>$ chi 2 & 0.0000 & 0.0000 & 0.0000 & 0.0000 \\
\hline
\end{tabular}

Notes: Random-effects probit regression.

$\mathrm{h}=$ hours of water use by upstream user.

${ }^{*}$ Significance levels (two-sided) at $10 \%$.

${ }_{* * *}^{* *}$ Significance levels (two-sided) at $5 \%$.

*** Significance levels (two-sided) at $1 \%$.

Table 5. Predicted probabilities of downstream users' reaction

\begin{tabular}{|c|c|c|c|c|}
\hline & Satisfaction $(\%)$ & Silent $(\%)$ & Dissatisf. (\%) & Punishment (\%) \\
\hline \multicolumn{5}{|l|}{ Abundance } \\
\hline$h \in[0,4[$ & 68.04 & 14.46 & 17.37 & 3.30 \\
\hline$h \in[4,6[$ & 67.28 & 18.83 & $4.57 \%$ & 9.37 \\
\hline$h \in] 6,8]$ & 24.12 & 20.20 & 38.39 & 22.08 \\
\hline$h \in] 8,12]$ & 6.26 & 7.75 & 32.82 & 51.53 \\
\hline \multicolumn{5}{|l|}{ Scarcity } \\
\hline$h \in[4,6[$ & 52.72 & 21.15 & 20.19 & 1.40 \\
\hline$h=6$ & 49.92 & 26.74 & 13.40 & 3.95 \\
\hline$h \in] 6,8]$ & 26.09 & 12.18 & 44.87 & 18.21 \\
\hline$h \in] 8,12]$ & 21.23 & 8.03 & 30.78 & 44.76 \\
\hline
\end{tabular}

Note: Based on the random effects probit regression reported in Table 4.

likelihoods are $10.84 \%$ and $8.97 \%$, respectively, and $5.83 \%$ and $9.11 \%$ in the scarcity treatment. In sum, alternation in the scarcity treatment is particularly strong between the extreme ends of the distribution (i.e., between $h \in] 8,12]$ and $h \in[0,4[$, which is not surprising as this leads to the highest possible efficiency gains. The discussed findings can be summarized in the following result. ${ }^{15}$

Result 3: State dependence of altruistic sharing is stronger in the abundance treatment than in the scarcity treatment. Furthermore, the likelihood to alternate between altruistic and selfish sharing is higher in the scarcity treatment than in the abundance treatment, particularly for large deviations from equal sharing.

So far, we ignored any effect that the reaction of downstream users might have on the strategy choice of upstream users. If downstream users disagree with upstream users' selfish sharing and their reaction forces upstream users to refrain from selfish sharing, it may be difficult to sustain an alternation strategy between selfish and altruistic sharing.

To study the influence of punishment, which is the strongest reaction option, we replace the dummy variables that account for the water allocation in the previous round with new dummy variables that account for both the water allocation and the consequent punishment decision made by the downstream user. As with altruistic and equal sharing punishment is very uncommon, we only do so for selfish sharing. ${ }^{16}$ This allows us to study the effectiveness of punishment in making the upstream user abandon selfish sharing. In particular, to allow for the possibility of punishment we split the dummy variables " $h(r-1) \epsilon] 8,12] "$ and " $h(r-1) \epsilon] 6,8] "$ into " $h(r-1) \epsilon] 8$, 
Table 6. Upstream users' strategy choice

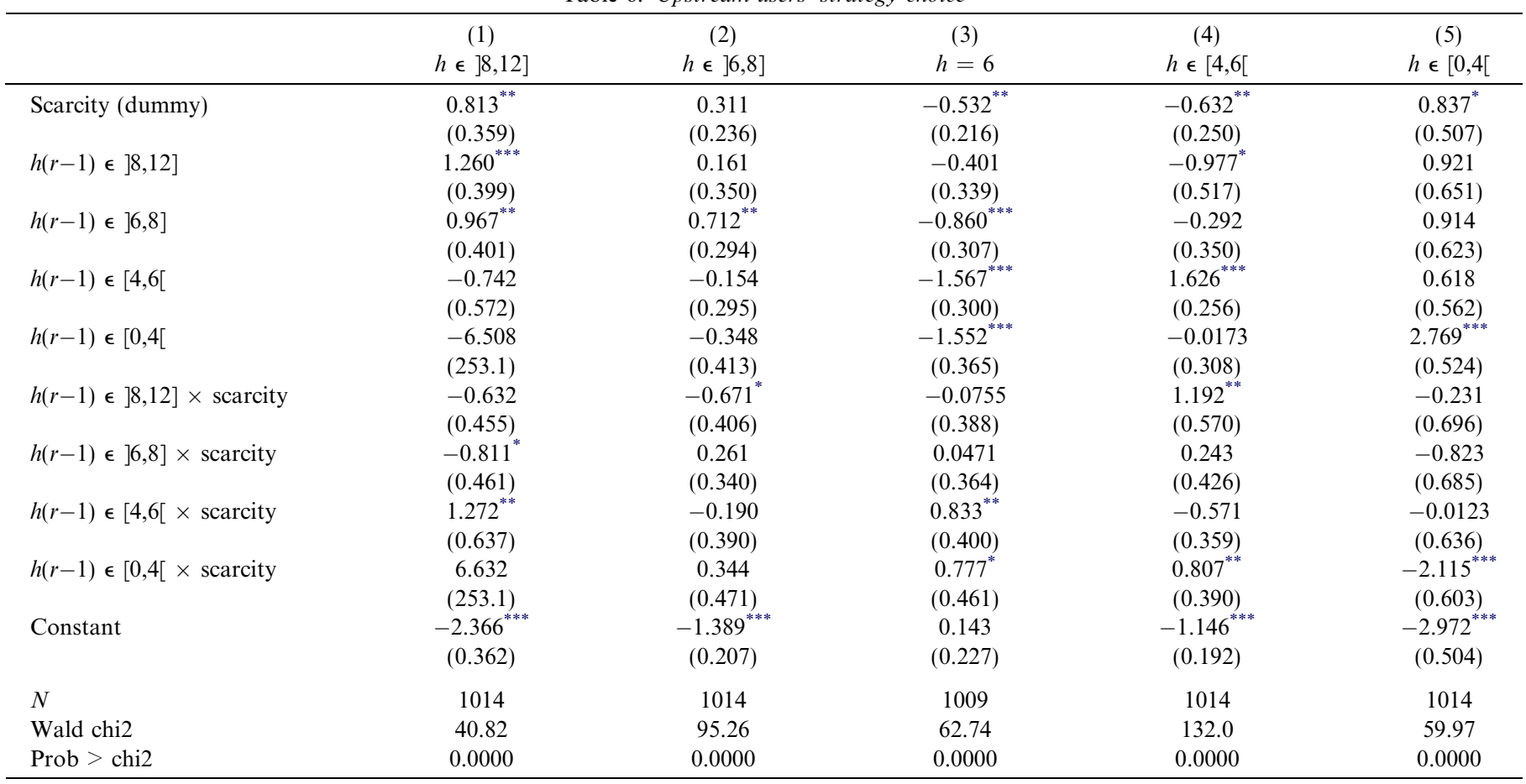

Note: Random-effects (dynamic) probit model. Standard errors between brackets.

$\mathrm{h}=$ hours of water use by upstream user. The first rounds of both treatments are not included.

${ }^{*}$ Significance levels (two-sided) at $10 \%$.

${ }^{* *}$ Significance levels (two-sided) at $5 \%$.

Significance levels (two-sided) at $1 \%$.

Table 7. Predicted probabilities of upstream users' strategy choice

\begin{tabular}{|c|c|c|c|c|c|}
\hline & $h \in] 8,12](\%)$ & $h \in] 6,8](\%)$ & $h=6(\%)$ & $h \in[4,6[(\%)$ & $h \in[0,4[(\%)$ \\
\hline \multicolumn{6}{|l|}{ Abundance } \\
\hline$h(r-1) \in] 8,12]$ & 24.27 & 15.14 & 43.46 & 3.41 & 9.04 \\
\hline$h(r-1) \in] 6,8]$ & 18.87 & 28.49 & 32.39 & 10.84 & 8.97 \\
\hline$h(r-1)=6$ & 6.78 & 12.19 & 53.63 & 16.25 & 2.62 \\
\hline$h(r-1) \in[4,6[$ & 2.50 & 9.78 & 18.23 & 65.97 & 6.23 \\
\hline$h(r-1) \in[0,4[$ & 0.00 & 7.25 & 18.47 & 15.89 & 44.74 \\
\hline \multicolumn{6}{|l|}{ Scarcity } \\
\hline$h(r-1) \in] 8,12]$ & 28.00 & 9.14 & 29.05 & 8.97 & 17.29 \\
\hline$h(r-1) \in] 6,8]$ & 18.91 & 46.49 & 22.19 & 5.83 & 9.11 \\
\hline$h(r-1)=6$ & 16.37 & 18.29 & 40.21 & 6.34 & 8.18 \\
\hline$h(r-1) \in[4,6[$ & 25.95 & 11.66 & 23.73 & 26.72 & 15.91 \\
\hline$h(r-1) \in[0,4[$ & 18.38 & 18.21 & 22.91 & 19.80 & 16.70 \\
\hline
\end{tabular}

Note: Based on the random effects probit regression reported in Table 6.

$12]+$ not punished", “ $h(r-1) \in] 8, \quad 12]+$ punished", " $h(r-1) \epsilon] 6,8]+$ not punished," and " $h(r-1) \epsilon] 6,8]+$ punished".

As we focus on upstream users' alternation between selfish and altruistic sharing, we estimate this specification for the scarcity treatment only. However, by doing so, the start of the observations does not coincide with the start of the process. People have played another treatment before, and with the same people as the pairs of upstream and downstream users remain fixed. Therefore, a standard random effects model is not appropriate. While there are various ways to deal with this "initial observations" problem, we use the method proposed by Wooldridge (2005), which consists of modeling the distribution of the unobserved effect conditional on the initial value. In practice, this is done through the inclusion of the decisions in the first round (of the scarcity treatment) as additional covariates. Table 8 presents the results, while Table 9 presents the associated predicted probabilities conditional on the upstream user's distribution (and downstream user's choice of the punishment option) in the previous round.

We find that punishment does not exert a statistically significant influence on the upstream user's strategy choice. The coefficients of the variables " $h(r-1) \in] 8,12]+$ not punished", and " $h(r-1) \epsilon] 8,12]+$ punished" are not statistically different from each other in any of the five models. Neither are the coefficients of " $h(r-1) \epsilon] 6,8]+$ not punished" and 
Table 8. Water distribution and the response to downstream users' reaction

\begin{tabular}{|c|c|c|c|c|c|}
\hline & $\begin{array}{c}(1) \\
h \in] 8,12]\end{array}$ & $\begin{array}{c}(2) \\
h \in] 6,8]\end{array}$ & $\begin{array}{c}(3) \\
h=6\end{array}$ & $\begin{array}{c}(4) \\
h \in[4,6[\end{array}$ & $\begin{array}{c}(5) \\
h \in[0,4[\end{array}$ \\
\hline$h(r-1) \in] 8,12]+$ not punished & $\begin{array}{l}0.620^{* *} \\
(0.283)\end{array}$ & $\begin{array}{l}-0.629^{* *} \\
(0.302)\end{array}$ & $\begin{array}{c}0.105 \\
(0.306)\end{array}$ & $\begin{array}{c}0.255 \\
(0.322)\end{array}$ & $\begin{array}{l}0.656^{*} \\
(0.356)\end{array}$ \\
\hline$h(r-1) \in] 8,12]+$ punished & $\begin{array}{l}0.708^{* *} \\
(0.308)\end{array}$ & $\begin{array}{l}-0.520^{*} \\
(0.307)\end{array}$ & $\begin{array}{l}-0.468 \\
(0.346)\end{array}$ & $\begin{array}{c}0.177 \\
(0.359)\end{array}$ & $\begin{array}{l}0.738^{* *} \\
(0.356)\end{array}$ \\
\hline$h(r-1) \in] 6,8]+$ not punished & $\begin{array}{c}0.162 \\
(0.268)\end{array}$ & $\begin{array}{l}0.650^{* * *} \\
(0.239)\end{array}$ & $\begin{array}{l}-0.413 \\
(0.254)\end{array}$ & $\begin{array}{c}0.132 \\
(0.284)\end{array}$ & $\begin{array}{l}0.0203 \\
(0.342)\end{array}$ \\
\hline$h(r-1) \in] 6,8]+$ punished & $\begin{array}{c}0.241 \\
(0.395)\end{array}$ & $\begin{array}{c}0.465 \\
(0.333)\end{array}$ & $\begin{array}{c}0.00194 \\
(0.383)\end{array}$ & $\begin{array}{l}-5.057 \\
(983.9)\end{array}$ & $\begin{array}{l}-0.177 \\
(0.587)\end{array}$ \\
\hline$h(r-1) \in[4,6[$ & $\begin{array}{l}0.650^{* *} \\
(0.298)\end{array}$ & $\begin{array}{l}-0.425 \\
(0.289)\end{array}$ & $\begin{array}{l}-0.384 \\
(0.291)\end{array}$ & $\begin{array}{l}0.654^{* *} \\
(0.306)\end{array}$ & $\begin{array}{l}0.581^{*} \\
(0.333)\end{array}$ \\
\hline$h(r-1) \in[0,4[$ & $\begin{array}{c}0.212 \\
(0.314)\end{array}$ & $\begin{array}{c}-0.0489 \\
(0.276)\end{array}$ & $\begin{array}{l}-0.412 \\
(0.321)\end{array}$ & $\begin{array}{l}0.753^{* * *} \\
(0.284)\end{array}$ & $\begin{array}{c}0.408 \\
(0.331)\end{array}$ \\
\hline$h(r-1) \in] 8,12]$ & $\begin{array}{l}1.004^{* *} \\
(0.481)\end{array}$ & & & & \\
\hline$h(r-1) \in] 6,8]$ & & $\begin{array}{c}0.745^{* * *} \\
(0.273)\end{array}$ & & & \\
\hline$h(r-1)=6$ & & & $\begin{array}{l}2.445^{* * *} \\
(0.441)\end{array}$ & & \\
\hline$h(r-1) \in[4,6[$ & & & & $\begin{array}{l}1.235^{* * *} \\
(0.385)\end{array}$ & \\
\hline$h(r-1) \in[0,4[$ & & & & & $\begin{array}{l}2.730^{* * *} \\
(0.701)\end{array}$ \\
\hline Constant & $\begin{array}{c}-1.743^{* * *} \\
(0.258)\end{array}$ & $\begin{array}{c}-1.318^{* * *} \\
(0.205)\end{array}$ & $\begin{array}{c}-1.307^{* * *} \\
(0.295)\end{array}$ & $\begin{array}{c}-2.032^{* * *} \\
(0.242)\end{array}$ & $\begin{array}{c}-2.325^{\text {*** }} \\
(0.315)\end{array}$ \\
\hline$N$ & 701 & 701 & 701 & 701 & 701 \\
\hline Wald chi2 & 17.91 & 53.67 & 54.00 & 28.15 & 27.62 \\
\hline Prob $>$ chi 2 & 0.0000 & 0.0000 & 0.0000 & 0.0000 & 0.0000 \\
\hline
\end{tabular}

Note: Random-effects (dynamic) probit model. Standard errors between brackets. Observations of scarcity treatment only.

$\mathrm{h}=$ hours of water use by upstream user.

${ }^{*}$ Significance levels (two-sided) at $10 \%$.

${ }_{* * *}^{* *}$ Significance levels (two-sided) at $5 \%$.

*** Significance levels (two-sided) at 1\%.

Table 9. Predicted probabilities of upstream users' strategy choice

\begin{tabular}{|c|c|c|c|c|c|}
\hline & $h \in] 8,12](\%)$ & $h \in] 6,8](\%)$ & $h=6(\%)$ & $h \in[4,6[(\%)$ & $h \in[0,4[(\%)$ \\
\hline$h(r-1) \in] 8,12]+$ not punished & 23.81 & 11.10 & 36.57 & 10.54 & 18.19 \\
\hline$h(r-1) \in] 8,12]+$ punished & 25.58 & 12.66 & 27.68 & 10.24 & 19.85 \\
\hline$h(r-1) \in] 6,8]+$ not punished & 15.81 & 41.71 & 25.86 & 9.46 & 10.14 \\
\hline$h(r-1)=6$ & 13.45 & 20.89 & 36.10 & 7.58 & 17.03 \\
\hline$h(r-1) \in[4,6[$ & 24.41 & 13.67 & 26.93 & 19.72 & 17.03 \\
\hline$h(r-1) \in[0,4[$ & 16.58 & 21.29 & 26.18 & 20.13 & 15.58 \\
\hline
\end{tabular}

Note: Based on the random effects probit regression reported in Table 8.

" $h(r-1) \epsilon] 6,8]+$ punished" statistically different from each other. This is consistent with Ostrom's (1990) observation that punishment often provokes resentment and unwillingness to rule compliance in the future.

One could argue, however, that also the expression of dissatisfaction might possibly influence upstream user's strategy choice, and should therefore be taken into account as well. Therefore, we estimated an additional model (reported in Table 12 in the Appendix) that merges the two protest options (punishment and the expression of dissatisfaction). Also in these models no statistically significant effects are found. We summarize these findings in the following result.

Result 4: Upstream users do not change their allocation behavior in response to downstream users' dissatisfaction or punishment.

\section{CONCLUSION}

In this article, we studied how people in rural Tanzania bargain over the use of scarce water resources when facing tradeoffs between income maximization, respect for equity, and/or efficiency maximization. For this purpose, we organized a distribution game that simulates the distribution of (access to) irrigation water between upstream and downstream users. Our data reject the prediction of standard economic theory that individuals only care about material self-interest, and confirm a strong preference for equity. This is not surprising given the strength of egalitarian norms in small-scale societies in Sub-Saharan Africa. Moreover, our data suggest that equal sharing is not driven out of fear of retaliation but due to an internalized preference for equity. This is supported by the 
observation that equal sharing is common even when in our game punishment costs are low (compared for instance with ultimatum games where distributors lose all income when their proposal gets rejected) and hence there is little room for strategic behavior. Also the observed ineffectiveness of punishment to alter upstream users' allocation behavior supports the idea that equal sharing is the result of an internalized preference for equity.

There might be an issue, however, if the strong preference for equity inhibits the implementation of efficiency-enhancing allocations. In our experiment, we found that in a scarcity treatment, where efficiency gains can only be obtained by deviating from equal sharing, many upstream users continue to choose for the equal split. Consequently, large amounts of resources remain unexploited. Yet, we also found indications that efficiency considerations are taken into account. We observed that compared to a basic treatment without such equity-efficiency conflict, the likelihood of selfish (and efficiency-enhancing) deviations from equal sharing is higher.

In this scarcity treatment, we also found a higher incidence of alternation between selfish and altruistic sharing, which makes it possible to reconcile efficiency and equity considerations. This result suggests that poor (and often illiterate) farmers are able to implement such more advanced alternation strategies without any outside support. Even though the asymmetric nature of irrigation water allocation (with fixed location asymmetries) may limit somewhat people's willingness to alternate, the use of such strategies could be substantially increased. Here is an important role for policymakers, to iden- tify existing welfare-enhancing institutions that respect local egalitarian norms and try to find ways to increase their scale of operation. Existing local institutions that reconcile equity and efficiency considerations such as any form of rotation scheme of local resources (such as labor, savings, among others) could form the basis for more formalized institutions for resource sharing, credit facilities, and social security systems. Policy makers could also be helpful in safeguarding such institutions by increasing their resilience to external shocks. As alternation strategies can only be successfully implemented when everyone uses the same (longer) time frame, the sustainability of these institutions may be jeopardized by economic shocks, which force people to deal with acute and short term needs. Policymakers could help secure locally existing institutions by offering insurance or credit services, among others, which can reduce the impact of economic shocks.

Finally, several variations to our experimental game can be designed to analyze the influence of further elements that are relevant in the real-life setting of irrigation systems. In particular, a provision stage could be added or the game could be played with more than two players, as was done by Cardenas et al. (2011). Furthermore, the interlocked nature of rural economies makes it relevant to analyze whether and how the definition of equitable water allocation varies with how the exchange of other socio-economic resources is organized. In addition, benefit sharing among the irrigators, possibly within social networks, is an important element that could be analyzed, as it may provide an additional way to reconcile equity and efficiency.

\section{NOTES}

1. Other methods have been used to analyze determinants of the functioning of irrigation water systems, such as econometric methods (e.g., Gorton et al., 2009; Meinzen-Dick et al., 2002), contingent valuation methods (e.g., Speelman, Frija, Buysse, \& Van Huylenbroeck, 2011) or the analysis of case study material (e.g., Wade, 1988). However, none of them are particularly useful to analyze strategic interaction among irrigation users.

2. Providing sufficient field referents may be required to make sure that subjects apply the relevant field heuristic. Indeed, as Harrison and List (2004, p. 1028) argue: "if the subject does not understand what the task is about, in the sense of knowing what actions are feasible and what the consequences of different actions might be, then control has been lost at a basic level”.

3. An irrigator is defined as the person in the household responsible for decisions on and cultivation of the irrigated plot. Not more than one person per household participated in the game.

4. Whether irrigators were assigned to be upstream or downstream users in the experiment was independent of their actual position in the irrigation schemes. In these irrigation systems, most irrigators have a neighbor located upstream and another downstream, and hence are confronted with both types of decisions.

5. With scarce resources it is more likely that producers find themselves in the lower end of the production function, where marginal returns are increasing. Such increasing marginal returns may be the result of high levels of water seepage, for example (see e.g., Lal Kalu et al. (1995)). The threshold in the production function is actually a dichotomous version of increasing marginal returns. Such threshold in the production function is also supported by studies on plant physiology. In the irrigation sites under study, the bulk of the sites are planted with maize and beans. The remainder of the area is planted with tomatoes, Chinese cabbage, and other vegetables. All these plants need an absolute minimum amount of water to grow and produce crops or fruits (Onwueme \& Sinha, 1991). If irrigation is below this level, plants will shrivel and can only be used as animal fodder or organic fertilizer. We assume that at this level of production, there is not much differentiation in terms of quality, and the value of the lost harvest is low.

6. Designing an experimental game that remained understandable to our participants, many of whom are illiterate, necessarily implied giving up some relevant elements. In particular, adding a provision stage to our game and playing the game with more than two players - although making our game more realistic - would necessarily force us to give up the relatively complex production function. The latter, however, is necessary to analyze equity-efficiency trade-offs, the focus of our study. Cardenas et al. (2011), for example, included a provision stage prior to an allocation stage in an irrigation experiment with groups of four irrigators. The dynamics observed in their game are of a complex nature, which indicates that adding these two more realistic elements to our design would have complicated the game too much for our participants.

7. We decided to use a within-subject design instead of a betweensubject design because of the following advantages. First, we need fewer participants as all participants will go through both treatments. Second, there is less measurement error due to variation in participant disposition, since there are fewer participants and participants' predisposition is likely to be consistent across both treatments. Third, these data can be analyzed with panel data regression techniques, which allow us to control for unobserved individual heterogeneity providing more efficient test results. Furthermore, we do not anticipate any interference between the treatments or any learning effects, which make the results dependent on the order of the treatments. 
8. Whereas "income maximization" refers to one's individual production only, "efficiency" refers to the aggregate production relative to the available inputs, and "equity" refers to the distribution of the aggregate production among the two players, irrespective of the resource (water) endowment given.

9. To analyze the optimizing behavior of these smallholder subsistence farmers, different approaches can be used. In particular, as the subjects are producers a profit maximization focus might be considered. However, as they also consume (at least part) of their production, a utility maximization approach is equally appropriate. We choose for the latter focus as it is most consistent with the approach used in experimental economics. We assume that our subjects are utility maximizers, and that in case of narrow material self-interest, utility is only dependent on one's own income, which is net of costs.

10. Note that even after including punishment costs, such alternation strategy remains superior. To show this, imagine the smallest possible alternation strategy ( $7 \mathrm{~h}$ for the upstream user in one round, $7 \mathrm{~h}$ for the downstream user in the next round), which leads to an efficiency gain of $2 \times 75$ TSH relative to the equal split strategy. When the upstream user is punished (we assume that this is only realistic if he/she has more than $6 \mathrm{~h}$ water access), this leads to an efficiency loss of $130 \mathrm{TSH}$ being the result of a 100 TSH cost for the upstream user and 30 TSH for the downstream user, which is lower than the efficiency gain of $150 \mathrm{TSH}$ of the alternation strategy relative to the equal split.

11. Remind that punishment costs are only $100 \mathrm{TSH}$, which are easily offset by opting for at least $8 \mathrm{~h}$ of water use.
12. We also observe that there is a peak at 4 and $8 \mathrm{~h}$. These distributions are more commonly chosen than the immediately surrounding options; which suggests that they are focal points. Keeping more than $8 \mathrm{~h}$ or less than $4 \mathrm{~h}$ drastically reduces aggregate production and increases inequality.

13. Both explanations are supported by an observed shift from altruistic to selfish sharing (and not to equal sharing). Of the 33 upstream users who shared water access altruistically in at least three out of the five rounds in the abundance treatment, 16 never opted for equal sharing in the scarcity treatment and 10 only did so in 1 round (out of the 10 rounds); and 20 opted for selfish sharing in the scarcity treatment in at least three out of the 10 rounds in the scarcity treatment.

14. Percentages do not sum up to $100 \%$, as each reaction option was analyzed in a separate model. As a consequence, we can only interpret the estimated effects within each separate model, not across models.

15. In order to give upstream users sufficient time to discover the feasibility of alternation strategies, we organized twice as many rounds in the scarcity treatment as in the abundance treatment. We also run the analyses with the same number of rounds in both treatments, by excluding the five last rounds of the scarcity treatment. Tables 10 and 11 in the Appendix present the results of the analyses of the downstream and upstream user, respectively. We find that the upstream user's tendency to alternate disappears, which confirms that successful implementation of alternation strategies requires sufficient time. The results of the analyses of downstream users' decisions are very similar to the results of the original model with all rounds included.

16. Whereas the punishment rate is $32.1 \%$ when upstream users opt for selfish sharing, punishment rates are only $4.7 \%$ and $2.0 \%$ when altruistic sharing and equal sharing are chosen, respectively.

\section{REFERENCES}

Baland, J. M., \& Platteau, J. P. (1996). Halting degradation of natural resources: Is there a role for rural communities. Oxford: Clarendon Press.

Baland, J. M., \& Platteau, J. P. (1998). Wealth inequality and efficiency in the commons, Part II: The regulated case. Oxford Economic Papers, 50(1), 1-22.

Bardhan, P. (2000). Irrigation and cooperation: An empirical analysis of 48 irrigation communities in South India. Economic Development and Cultural Change, 48, 847-865.

Bolton, G., \& Ockenfels, A. (2000). ERC - A theory of equity, reciprocity and competition. American Economic Review, 90, 166-193.

Camerer, C. F. (2003). Behavioral game theory: Experiments in strategic interaction. Princeton: Princeton University Press.

Cardenas, J. C., \& Carpenter, J. (2008). Behavioural development economics: Lessons from field labs in the developing world. Journal of Development Studies, 44(3), 311-338.

Cardenas, J. C., Rodriguez, L. A., \& Johnson, N. (2011). Collective action for watershed management: Field experiments in Colombia and Kenya. Environment and Development Economics, 16(3), 275-303.

Chakravorty, U., \& Roumasset, J. (1991). Efficient spatial allocation of irrigation water. American Journal of Agricultural Economics, 73(1), $165-173$

Charness, G., \& Rabin, M. (2002). Understanding social preferences with simple tests. Quarterly Journal of Economics, 117, 817-869.

Cochran, J., \& Ray, I. (2009). Equity reexamined: A study of communitybased rainwater harvesting in Rajasthan, India. World Development, $37(2), 435-444$.

Cooper, D. J., \& Kagel, J. H. (2010). Other regarding preferences: A selective survey of experimental results. In J. Kagel, \& A. Roth (Eds.). The handbook of experimental economics (Vol. 2). Princeton: Princeton University Press

Di Falco, S., \& Bulte, E. (2011). A dark side of social capital? Kinship, consumption and savings. Journal of Development Studies, 47(8), $1128-1151$.
Engelmann, D., \& Strobel, M. (2004). Inequality aversion, efficiency, and maximin preferences in simple distribution experiments. American Economic Review, 94(4), 857-969.

Fehr, E., \& Schmidt, K. M. (1999). A theory of fairness, competition and cooperation. Quarterly Journal of Economics, 114(3), 817-868.

Ferguson, C. A. (1992). Water allocation, inefficiency and inequity in a government irrigation system. Journal of Development Economics, $38(1), 165-182$.

Forsythe, R., Horowitz, J. L., Savin, N. E., \& Sefton, M. (1994). Fairness in simple bargaining experiments. Games and Economic Behavior, 6(3), 347-369.

Gorton, M., Sauer, J., Peshevski, M., Bosev, D., Shekerinov, D., \& Quarrie, S. (2009). Water communities in the Republic of Macedonia: An empirical analysis of membership satisfaction and payment behavior. World Development, 37(12), 1951-1963.

Gowdy, J., Iorgulescu, R., \& Onyeiwu, S. (2003). Fairness and retaliation in a rural Nigerian village. Journal of Economic Behavior \& Organization, 52(4), 469-479.

Grolleau, G., Mzoughi, N., \& Sutan, A. (2009). The impact of envyrelated behaviors on development. Journal of Economic Issues, 63, 795-803.

Güth, W., Schmittberger, R., \& Schwarze, B. (1982). An experimental analysis of ultimatum bargaining. Journal of Economic Behavior \& Organization, 3, 367-388.

Harrison, G. W., \& List, J. A. (2004). Field experiments. Journal of Economic Literature, 42(4), 1009-1055.

Henrich, J., Boyd, R., Bowles, S., Camerer, C., Fehr, E., \& Gintis, H. (2004). Foundations of human sociality: Economic experiments and ethnographic evidence from fifteen small-scale societies. Oxford: Oxford University Press.

Lal Kalu, I., Nidhi Paudyal, G., \& Das Gupta, A. (1995). Equity and efficiency issues in irrigation water distribution. Agricultural Water Management, 28, 335-348. 
Meinzen-Dick, R., Raju, K. V., \& Gulati, A. (2002). What affects organization and collective action for managing resources? Evidence from canal irrigation systems in India. World Development, 30(4), 649-666.

Mkavidanda, T., \& Kaswamila, A. (2001). The role of traditional irrigation systems (vinyungu) in alleviating poverty in Iringa rural district, Tanzania. REPOA Research Report, 01(2).

Onwueme, I. C., \& Sinha, T. D. (1991). Field crop production in tropical Africa: Principles and practice. Technical Centre for Agricultural and Rural Cooperation CTA. Ede, Netherlands.

Ostrom, E. (1990). Governing the commons: The evolution of institutions for collective action. New York: Cambridge University Press.

Ostrom, E., \& Gardner, R. (1993). Coping with asymmetries in the commons: Self-governing irrigation systems can work. Journal of Economic Perspectives, 7(4), 93-112.

Pilutla, M. M., \& Murnighan, J. K. (1995). Being fair or appearing fair: Strategic behavior in ultimatum bargaining. Academy of Management Journal, 38, 1408-1426.

Pinheiro, J. C., \& Bates, D. M. (2000). Mixed effects models in $S$ and $S$ plus. New York: Springer-Verlag.

Platteau, J. P. (2000). Institutions, social norms and economic development. Amsterdam: Harwood.

Platteau, J. P. (2006). Solidarity norms and institutions in village societies: Static and dynamic considerations. In S. C. Kolm, \& J. M. Ythier (Eds.). Handbook of the economics of giving, altruism and reciprocity (Vol. I, pp. 819-886). Amsterdam: North-Holland.

Ray, I., \& Williams, J. (2002). Locational asymmetry and the potential for cooperation on a canal. Journal of Development Economics, 67(1), $129-155$.
Speelman, S., Frija, A., Buysse, J., \& Van Huylenbroeck, G. (2011). The importance of irrigation water rights: Lessons from South Africa and Tunisia. Water Policy, 13, 663-676.

Stewart, M. B. (2006). Redprob: A Stata program for the Heckman estimator of the random effects dynamic probit model. mimeo, University of Warwick.

United Republic of Tanzania (2006a). Agro-ecological zone, Mufindi District. Retrieved November 15, 2010, from Ministry of Agriculture, Food Security and Cooperatives, Dar es Salaam.

United Republic of Tanzania (2006b). National sample census of agriculture 2002/2003. Small holder agriculture, Vol. II: Crop sector - National report.

Wade, R. (1988). The management of irrigation systems: How to evoke trust and avoid prisoner's dilemma. World Development, 16(4), 489-500.

Wooldridge, J. (2005). Simple solutions to the initial conditions problem in dynamic, nonlinear panel data models with unobserved heterogeneity. Journal of Applied Econometrics, 20(1), 39-54.

\section{APPENDIX A. ADDITIONAL ANALYSES}

Table 10. Downstream users' reaction $(2 \times 5$ rounds $)$

\begin{tabular}{|c|c|c|c|c|}
\hline & $\begin{array}{c}(1) \\
\text { Satisfaction }\end{array}$ & $\begin{array}{c}(2) \\
\text { Silent }\end{array}$ & $\begin{array}{c}\text { (3) } \\
\text { Dissatisf. }\end{array}$ & $\begin{array}{c}\text { (4) } \\
\text { Punishment }\end{array}$ \\
\hline Scarcity (dummy) & $\begin{array}{c}-0.682^{* * *} \\
(0.256)\end{array}$ & $\begin{array}{l}0.578^{* *} \\
(0.271)\end{array}$ & $\begin{array}{l}0.0258 \\
(0.303)\end{array}$ & $\begin{array}{c}-0.0431 \\
(0.480)\end{array}$ \\
\hline$h(r-1) \in] 8,12]$ & $\begin{array}{c}-3.453^{* * *} \\
(0.617)\end{array}$ & $\begin{array}{c}-0.998^{* *} \\
(0.462)\end{array}$ & $\begin{array}{l}1.354^{* * *} \\
(0.326)\end{array}$ & $\begin{array}{l}2.730^{* * *} \\
(0.470)\end{array}$ \\
\hline$h(r-1) \in] 6,8]$ & $\begin{array}{c}-2.018^{* * *} \\
(0.337)\end{array}$ & $\begin{array}{l}0.0692 \\
(0.339)\end{array}$ & $\begin{array}{l}1.523^{* * *} \\
(0.328)\end{array}$ & $\begin{array}{l}1.526^{* * *} \\
(0.443)\end{array}$ \\
\hline$h(r-1) \in[4,6[$ & $\begin{array}{c}0.336 \\
(0.295)\end{array}$ & $\begin{array}{l}-0.133 \\
(0.321)\end{array}$ & $\begin{array}{l}-0.543 \\
(0.374)\end{array}$ & $\begin{array}{c}0.437 \\
(0.441)\end{array}$ \\
\hline$h(r-1) \in[0,4[$ & $\begin{array}{c}0.262 \\
(0.378)\end{array}$ & $\begin{array}{l}-0.322 \\
(0.385)\end{array}$ & $\begin{array}{c}0.430 \\
(0.413)\end{array}$ & $\begin{array}{l}-0.169 \\
(0.589)\end{array}$ \\
\hline$h(r-1) \in] 8,12] \times$ scarcity & $\begin{array}{l}2.128^{* * *} \\
(0.647)\end{array}$ & $\begin{array}{l}-0.726 \\
(0.611)\end{array}$ & $\begin{array}{c}-0.0764 \\
(0.423)\end{array}$ & $\begin{array}{l}-0.239 \\
(0.573)\end{array}$ \\
\hline$h(r-1) \in] 6,8] \times$ scarcity & $\begin{array}{c}0.684 \\
(0.426)\end{array}$ & $\begin{array}{c}-1.088^{* *} \\
(0.450)\end{array}$ & $\begin{array}{c}0.291 \\
(0.422)\end{array}$ & $\begin{array}{l}-0.280 \\
(0.595)\end{array}$ \\
\hline$h(r-1) \in[4,6[\times$ scarcity & $\begin{array}{l}-0.284 \\
(0.453)\end{array}$ & $\begin{array}{l}-0.278 \\
(0.470)\end{array}$ & $\begin{array}{l}1.265^{* *} \\
(0.537)\end{array}$ & $\begin{array}{l}-1.134 \\
(1.026)\end{array}$ \\
\hline$h(r-1) \in[0,4[\times$ scarcity & $\begin{array}{c}0.475 \\
(0.479)\end{array}$ & $\begin{array}{l}-0.264 \\
(0.507)\end{array}$ & $\begin{array}{l}-0.270 \\
(0.590)\end{array}$ & $\begin{array}{l}-0.611 \\
(1.045)\end{array}$ \\
\hline Constant & $\begin{array}{l}0.615^{* *} \\
(0.267)\end{array}$ & $\begin{array}{c}-1.582^{* * * *} \\
(0.295)\end{array}$ & $\begin{array}{c}-1.988^{* * *} \\
(0.279)\end{array}$ & $\begin{array}{c}-2.801^{* * *} \\
(0.412)\end{array}$ \\
\hline Observations & 780 & 780 & 780 & 778 \\
\hline chi2 & 131.0 & 26.40 & 88.98 & 70.71 \\
\hline Prob $>$ chi 2 & 0.0000 & 0.0000 & 0.0000 & 0.0000 \\
\hline
\end{tabular}

Note: Random-effects probit regression.

$\mathrm{h}=$ hours of water use by upstream user

${ }^{*}$ Significance levels (two-sided) at $10 \%$.

${ }^{* *}$ Significance levels (two-sided) at $5 \%$.

${ }^{* * *}$ Significance levels (two-sided) at $1 \%$. 
Table 11. Upstream users' strategy choice $(2 \times 5$ rounds $)$

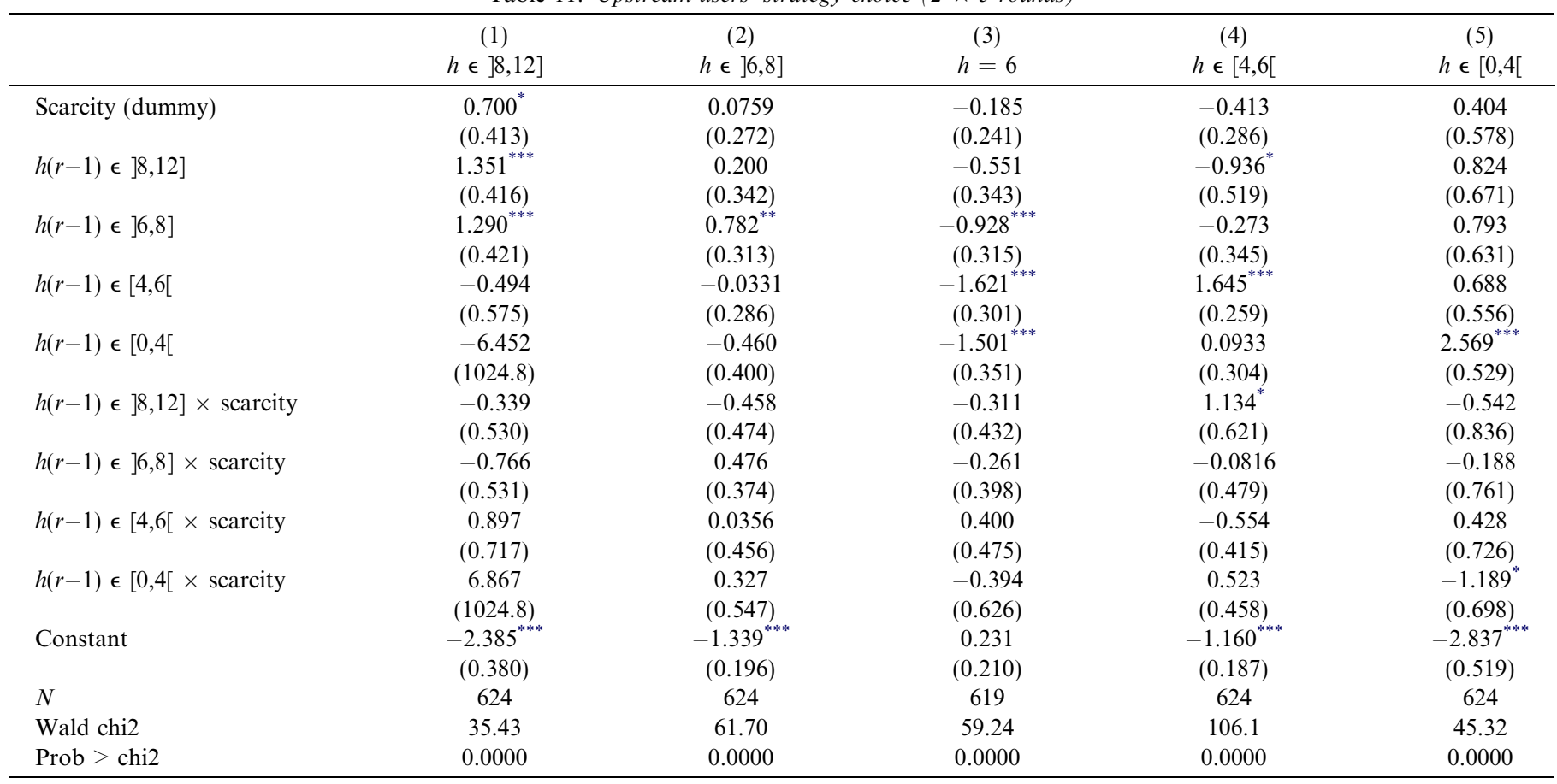

Note: Random-effects (dynamic) probit model. Standard errors between brackets.

$\mathrm{h}=$ hours of water use by upstream user. The first rounds of both treatments are not included.

${ }^{*}$ Significance levels (two-sided) at $10 \%$.

${ }^{* *}$ Significance levels (two-sided) at $5 \%$.

${ }^{* * *}$ Significance levels (two-sided) at $1 \%$. 
Table 12. Water distribution and the response to downstream users' reaction

\begin{tabular}{|c|c|c|c|c|c|}
\hline & $\begin{array}{c}(1) \\
h \in] 8,12]\end{array}$ & $\begin{array}{c}(2) \\
h \in] 6,8]\end{array}$ & $\begin{array}{c}(3) \\
h=6\end{array}$ & $\begin{array}{c}(4) \\
h \in[4,6[\end{array}$ & $\begin{array}{c}(5) \\
h \in[0,4[\end{array}$ \\
\hline$h(r-1) \in] 8,12]+$ no protest & $\begin{array}{c}0.231 \\
(0.376)\end{array}$ & $\begin{array}{l}-0.449 \\
(0.423)\end{array}$ & $\begin{array}{c}0.222 \\
(0.408)\end{array}$ & $\begin{array}{c}0.284 \\
(0.435)\end{array}$ & $\begin{array}{l}0.995^{* *} \\
(0.468)\end{array}$ \\
\hline$h(r-1) \in] 8,12]+$ protest & $\begin{array}{l}0.803^{* * * *} \\
(0.275)\end{array}$ & $\begin{array}{l}-0.616^{* *} \\
(0.267)\end{array}$ & $\begin{array}{l}-0.278 \\
(0.289)\end{array}$ & $\begin{array}{c}0.197 \\
(0.307)\end{array}$ & $\begin{array}{l}0.605^{*} \\
(0.327)\end{array}$ \\
\hline$h(r-1) \in] 6,8]+$ no protest & $\begin{array}{l}-0.001 \\
(0.379)\end{array}$ & $\begin{array}{l}0.733^{* *} \\
(0.301)\end{array}$ & $\begin{array}{l}-0.239 \\
(0.351)\end{array}$ & $\begin{array}{l}0.0139 \\
(0.400)\end{array}$ & $\begin{array}{c}0.059 \\
(0.496)\end{array}$ \\
\hline$h(r-1) \in] 6,8]+$ protest & $\begin{array}{l}0.275 \\
(0.271)\end{array}$ & $\begin{array}{l}0.545^{* *} \\
(0.250)\end{array}$ & $\begin{array}{l}-0.367 \\
(0.263)\end{array}$ & $\begin{array}{l}-0.009 \\
(0.311)\end{array}$ & $\begin{array}{l}-0.043 \\
(0.355)\end{array}$ \\
\hline$h(r-1) \in[4,6[$ & $\begin{array}{l}0.631^{* *} \\
(0.296)\end{array}$ & $\begin{array}{l}-0.417 \\
(0.289)\end{array}$ & $\begin{array}{l}-0.380 \\
(0.291)\end{array}$ & $\begin{array}{l}0.652^{* *} \\
(0.308)\end{array}$ & $\begin{array}{l}0.592^{*} \\
(0.333)\end{array}$ \\
\hline$h(r-1) \in[0,4[$ & $\begin{array}{c}0.222 \\
(0.313)\end{array}$ & $\begin{array}{l}-0.048 \\
(0.276)\end{array}$ & $\begin{array}{l}-0.403 \\
(0.322)\end{array}$ & $\begin{array}{l}0.750^{* * *} \\
(0.283)\end{array}$ & $\begin{array}{c}0.410 \\
(0.331)\end{array}$ \\
\hline$h(r-1) \in] 8,12]$ & $\begin{array}{l}1.076^{* *} \\
(0.471)\end{array}$ & & & & \\
\hline$h(r-1) \in] 6,8]$ & & $\begin{array}{l}0.772^{* * *} \\
(0.277)\end{array}$ & & & \\
\hline$h(r-1)=6$ & & & $\begin{array}{l}2.427^{* * *} \\
(0.435)\end{array}$ & & \\
\hline$h(r-1) \in[4,6[$ & & & & $\begin{array}{l}1.217^{* * *} \\
(0.385)\end{array}$ & \\
\hline$h(r-1) \in[0,4[$ & & & & & $\begin{array}{c}2.725^{* * *} \\
(0.698)\end{array}$ \\
\hline Constant & $\begin{array}{c}-1.752^{* * *} \\
(0.254)\end{array}$ & $\begin{array}{c}-1.327^{* * *} \\
(0.207)\end{array}$ & $\begin{array}{c}-1.291^{* * *} \\
(0.293)\end{array}$ & $\begin{array}{c}-2.025^{* * *} \\
(0.242)\end{array}$ & $\begin{array}{c}-2.318^{* * *} \\
(0.314)\end{array}$ \\
\hline$N$ & 701 & 701 & 701 & 701 & 701 \\
\hline Wald chi2 & 20.93 & 53.04 & 53.48 & 29.97 & 28.35 \\
\hline Prob > chi 2 & 0.0000 & 0.0000 & 0.0000 & 0.0000 & 0.0000 \\
\hline
\end{tabular}

Note: Random-effects (dynamic) probit model. Standard errors between brackets.

$\mathrm{h}=$ hours of water use by upstream user. Observations of scarcity treatment only.

${ }^{*}$ Significance levels (two-sided) at $10 \%$.

${ }^{* *}$ Significance levels (two-sided) at $5 \%$.

${ }^{* * *}$ Significance levels (two-sided) at $1 \%$. 